\title{
Impact of Climate Change on the Frequency and Severity of Floods in the Pasig-Marikina River Basin
}

\author{
Cris Edward Monjardin ${ }^{1, *}$, Clarence Cabundocan ${ }^{1}$, Camille Ignacio $^{1}$ and Christian Jedd Tesnado \\ ${ }^{1}$ School of Civil, Environmental and Geolocgical Engineering, Mapua University, 1002 Intramuros Manila, Philippines
}

\begin{abstract}
This study assessed impacts of climate change on the frequency and severity of floods in the Pasig-Marikina River basin. Researchers used the historical data from PAG-ASA (Philippine Atmospheric, Geophysical and Astronomical Services Administration), specifically from Science Garden weather station. The historical data are coupled with a global climate model, the Hadley Center Model version 3 (HadCM3) to account for the natural variability of the climate system in the area. The observed data and the hydroclimatic data from HadCM3 was processed in Statistical Downscaling Model (SDSM) that results to rainfall data from 1961-2017 and change in temperature data from 2018-2048. A rainfall time series for the river basin was generated considering average seasonal effects in the area. A flood frequency curve was modelled. From that, flood value for 2048 was derived to be at $3950 \mathrm{cu} . \mathrm{m} / \mathrm{s}$. Additionally, the rapid urbanization in the area has contributed to the changes in the river system making it more vulnerable to floods. The results of this study supports the claim that the Pasig-Marikina River basin will be affected by the climate variability in terms of the increase in rainfall depth and average temperatures, higher flood frequency and more massive floods in the future. This study could help local government units to enforce improvement and mitigation in their area to prevent these from happening.
\end{abstract}

\section{Introduction}

The strategic location of the Philippines, lying beyond the western boundary of the massive Pacific Ocean, is the main cause why the country is subjected and exposed to extreme weather conditions. Over the past few years, the country experienced most of the world's strongest and destructive typhoons. Climate change, enhanced by global warming, induces the rising of sea surface and subsurface temperatures whilst contributes in producing stronger typhoons. These stronger typhoons carry more moisture that may also mean more precipitation. The highest recorded rainfall in Metro Manila was triggered by Typhoon Ketsana or locally known as Tropical Storm Ondoy. According to PAGASA, the rainfall produced by the typhoon itself amounted to 455 millimeters in $24 \mathrm{hrs}$. Among the affected areas by the flooding caused by Tropical Storm Ondoy, Marikina City was most devastated. The whole city was almost submerged in flood water, which went as high as 10 feet deep. The Marikina River overflowed transforming its streets to rivers. This traumatic consequence of floods has called for prevention or control flood damages in society.

In this context, Marikina River Basin as shown in Figure 1 was chosen to comprehensively simulate the impacts of future climate change and identify necessary actions. The study area is located east of Metropolitan Manila. This basin is the source of flood waters that inundates low lying areas along the Pasig-Marikina River and Mangahan Floodway [1]. The rivers that overflowed and resulted to exceptionally high and extensive flooding during the TS Ketsana event are the rivers that drain the basin. Studying the future impacts of climate change on the severity of flooding in rainfall in this basin may prevent or lessen future damages caused by flooding in the study area.

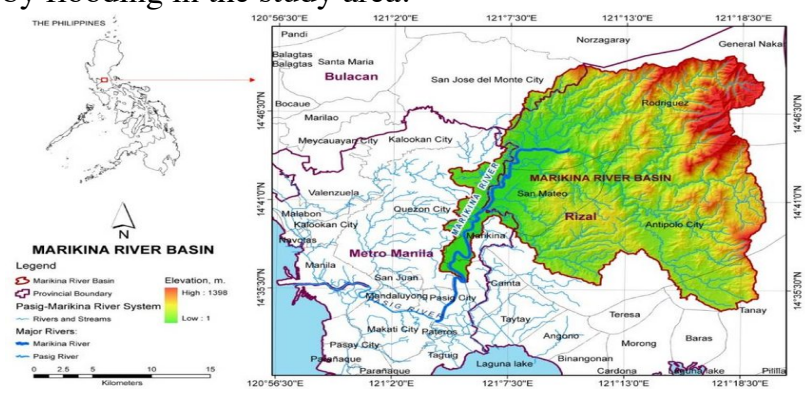

Fig. 1. Study Area

The main objective of the study is to determine the impact of climate change on the frequency and severity of floods in the Marikina River Basin. In line with the main objective, the specific objectives are to determine the rainfall pattern in Marikina River Basin, to gather historical records of the water level in Marikina River Basin, to assess the changes in land cover in Marikina River Basin affected by the flooding, and to predict future temperature and precipitation trends.

This study covers the assessment of the impacts of climate change in terms of precipitation and run-off in the Pasig-Marikina river basin. The analysis includes

* Corresponding author: cefmonjardin@mapua.edu.ph 
gathering of hydro climatological data from agencies, such as PAGASA and DRRM Marikina, collection and downscaling of GCM data through available software, identifying the climate change scenario of the river basin, and simulation of rainfall-runoff.

\section{Methodology}

The researchers adopted a quantitative method to analyze the data of rainfall and runoff. Simulation approach was implemented to understand and visualize the impact of climate change in study .

\subsection{Basin Delineation}

A 90-m spatial resolution Shuttle Radar Topography Mission - Digital Elevation Model (SRTM-DEM), available online at www.philgis.org, was analyzed through ArcGIS 10.6.1 to delineate the basin and determine the study area. ArcGIS's ArcHydro tools were the primary instruments processed the DEM..

The process includes manual selection of a point of interest which is based on the outlet generated by the application. The point was also based on a real map containing the study area. The nearest point or outlet selected in this process was the Manggahan Floodway which is also the lower boundary of the said basin. The generated basin is shown in Figure 2.

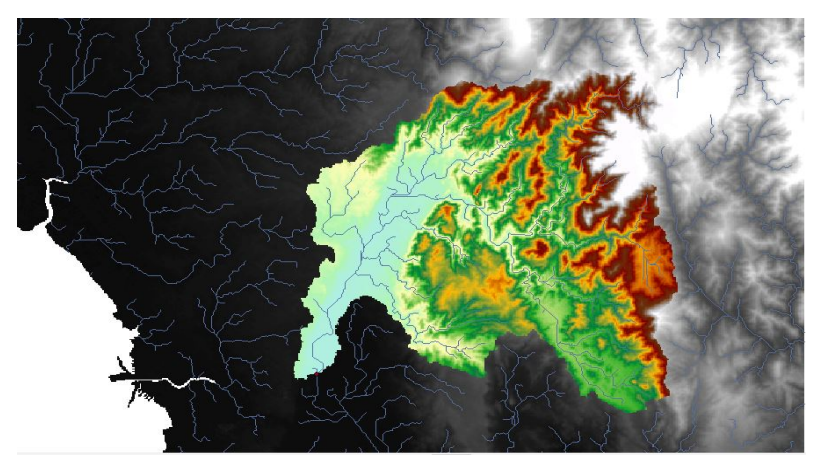

Fig. 2. Marikina River Basin generated by ARCGIS 10.6.1

\subsection{Observed Data Collection}

To understand how climate may change in the future for the area of concern, long-term observational records must be utilized. In the acquisition of data for rainfall and temperature, the researchers used the data from PAG-ASA-DOST. This agency collects date in respect of the atmospheric differences of the area on day-to-day basis. Precipitation, maximum temperature, and minimum temperature data for the years 1961-2017 were collected. These data were obtained from Science Garden in Quezon City since it is the closest weather station to the area of study.

Since, the climate in the Philippines is diverse due to differences in land and sea level temperatures; these temperatures must be recorded on long term basis at various climatic zones of the country.

\subsection{GCM Data Collection}

The GCM used was the UK Meteorological Office, HadCM3 forced by combined $\mathrm{CO} 2$ and albedo changes. For this study, the model run started in 1961 and forced with an estimate of historical forcing to 2017 and a projected future forcing scenario over 2018 - 2048 (30 years). This forcing is only an estimation of the real forcing. For the climate variability to be considered in this study, the researchers used a tool, named Statistical Downscaling Model (SDSM 5.2). HadCM3 data were also coupled in the downscaling technique. In Figure 3 the global map was divided into seven smaller windows: with each window surrounding a main land area, with the land-sea boundaries defined according to the HadCM3 land-sea mask. The predictor variables are supplied on a grid box by grid box basis. The researchers chose the region closes to the area of study. Three directories were assembled.

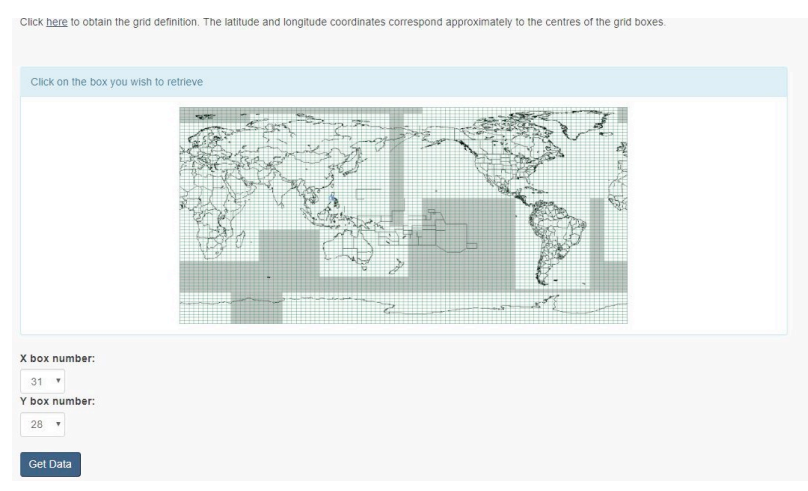

Fig. 3. The global window where the researchers collected the HadCM3 data

\subsection{Statistical Downscaling Model (SDSM)}

SDSM calculated statistical relationships based on multiple linear regression techniques between the predictors and the predictand. Using the observed atmospheric data, these relationships were developed [2]. Prior to data analysis, quality control for the data has been done to check whether there are missing values and to show the maximum and minimum values and other several information.

Likewise, screening of variables is completed to check and filter the data that the researchers will be using for analysis. The historical rainfall data is chosen as the predictand for this stage. The start date and end date are 01/01/1961 and 12/31/2001, using the NCEP as basis. There are 26 predictor variables from the directory of NCEP 1961-2001 but due to some restriction in SDSM, only 12 variables at a time can be run. In figure below, the highest value of correlation for every variable is shown in red. These data show the effect of each variable on the data for each month.

For the model calibration, the three predictors were used. There are twelve rows correspond to twelve months in a year from January to December. The first column is the intercepts while the second to fourth 
columns are comprised of the three parameters used and the last two columns are for the standard error and Rsquared statistics.

The next stage is to create a weather generator. The weather generator produces groups of artificial weather series daily given the observed climatic data/variables and the results of the model calibration.

Table 1. Sample result of Downscaled Annual Average Rainfall from 1961-2001

\begin{tabular}{|c|c|c|c|}
\hline Year & Rainfall & Year & Rainfall \\
\hline 1961 & 6.8 & 1985 & 6.6 \\
\hline 1965 & 5.8 & 1990 & 6.8 \\
\hline 1970 & 6.3 & 1995 & 6.8 \\
\hline 1975 & 6.9 & 2000 & 7.2 \\
\hline 1980 & 6.6 & 2001 & 7.2 \\
\hline
\end{tabular}

\subsection{Change in Temperature Data}

Raw dataset for temperature from 1961-2017 were collected from the available sources such as PAG-ASA. Meanwhile, projected change in temperature from 19612099 were quantified through the SDSM 5.2 tool.

Table 2. Sample result of Projected change in Temperature from Downscaled data

\begin{tabular}{|l|l|l|l|}
\hline Year & $\begin{array}{l}\text { Projected } \\
\text { Change }\end{array}$ & Year & $\begin{array}{l}\text { Projected } \\
\text { Change }\end{array}$ \\
\hline $\mathbf{1 9 6 1}$ & 0.845 & $\mathbf{2 0 4 1}$ & 0.575 \\
\hline $\mathbf{1 9 7 1}$ & 0.501 & $\mathbf{2 0 5 1}$ & 0.22 \\
\hline $\mathbf{1 9 8 1}$ & 0.27 & $\mathbf{2 0 6 1}$ & 0.475 \\
\hline $\mathbf{1 9 9 1}$ & 0.234 & $\mathbf{2 0 7 1}$ & 0.498 \\
\hline $\mathbf{2 0 0 1}$ & 0.405 & $\mathbf{2 0 8 1}$ & 0.944 \\
\hline $\mathbf{2 0 1 1}$ & 0.57 & $\mathbf{2 0 9 1}$ & 1.011 \\
\hline $\mathbf{2 0 2 1}$ & 0.723 & $\mathbf{2 0 9 9}$ & 1.034 \\
\hline $\mathbf{2 0 3 1}$ & 0.811 & & \\
\hline
\end{tabular}

\section{Results and Discussion}

\subsection{Rainfall Pattern based on Observed data}

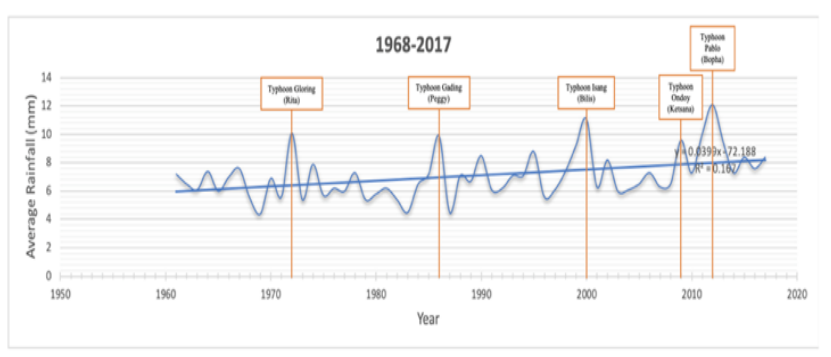

Fig. 4. Observed Average rainfall vs Year from 1968-2017

In Figure 4 the observed average rainfall is understood to have increased from the year 1961 to year 2017. The best fit trend line is $y=0.0399 x-72.188$. In 2012, a $12.1 \mathrm{~mm}$ rainfall was noted in the Science Garden; this is the highest average rainfall recorded from the time frame of 1961 to 2017. On the other hand, the lowest average rainfall recorded was on 1969. It was during this year when a $4.4 \mathrm{~mm}$ rainfall is observed. An increase in rainfall of $0.0399 \mathrm{~mm}$ per year likely

\subsection{Rainfall Pattern from Downscaled data}

\section{Downscaled Rainfall Data from 1961-2001}

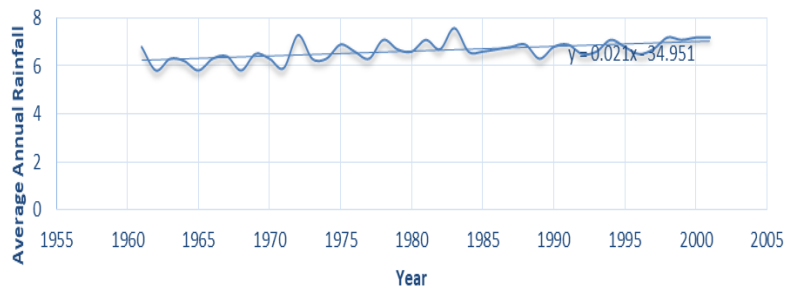

Fig. 5. Downscaled Average Rainfall vs Year from 1961-2001 Figure 5 depicts the rainfall pattern gathered from the SDSM 5.2, a downscaling tool for climate models. The best fit trend line is $\mathrm{y}=0.021 \mathrm{x}-34.951$. The highest average rainfall was tallied during the year 1983, while it was during 1962, 1965, and 1968 when the lowest mean rainfall is seen for the time frame of 1961-2001.

The downscaled precipitation data show that July, September and October have experienced the greatest increase in rainfall from 1961 to 2001. September has the highest incremental increase of $0.0744 \mathrm{~mm}$ per year. From these data, the results of downscaling support the historical records in saying that the dry season will be much affected by the impacts of climate change in terms of precipitation increase.

\subsection{Maximum Water level and Discharge in the Pasig-Marikina River}

The flood area of Sto. Niño is the most significant because it has an area of 517 sq. $\mathrm{km}$ that is located between mountain area and alluvial plain. It has an average estimated lag time of 5.5 hours which is influenced by the slope of the channel of about $1 / 1500$ and its length of $36.5 \mathrm{~km}$. The JICA Preparatory Study projected the release of $3211 \mathrm{~m}^{\wedge} 3 / \mathrm{s}$ at Sto. Niño for the year 2009. Manning's roughness coefficient of 0.033 is used to come up with the data.

Table 3 Sample collected Historical Data for Water level and discharge

\begin{tabular}{|l|l|l|}
\hline Year & $\begin{array}{l}\text { Water Level } \\
(\mathbf{m})\end{array}$ & $\begin{array}{l}\text { Discharge } \\
(\text { cu.m/s })\end{array}$ \\
\hline $\mathbf{1 9 5 8}$ & 14.78 & 507 \\
\hline $\mathbf{1 9 6 1}$ & 16.82 & 1161 \\
\hline $\mathbf{1 9 7 1}$ & 14.5 & 439 \\
\hline $\mathbf{1 9 8 6}$ & 20.92 & 2650 \\
\hline $\mathbf{1 9 9 4}$ & 16.33 & 980 \\
\hline $\mathbf{2 0 0 1}$ & 16.31 & 972 \\
\hline $\mathbf{2 0 0 9}$ & 22.16 & 3211 \\
\hline
\end{tabular}




\subsection{Rainfall vs Temperature}

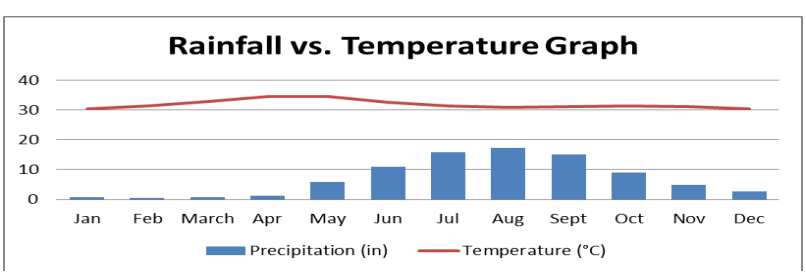

Fig. 6. Rainfall vs Temperature

Figure 6 shows climate graph of the Pasig-Marikina River Basin. It consists of monthly temperature and precipitation on the area. With these parameters, the climate in the area can be predicted.

\subsection{Temperature Change Projection}

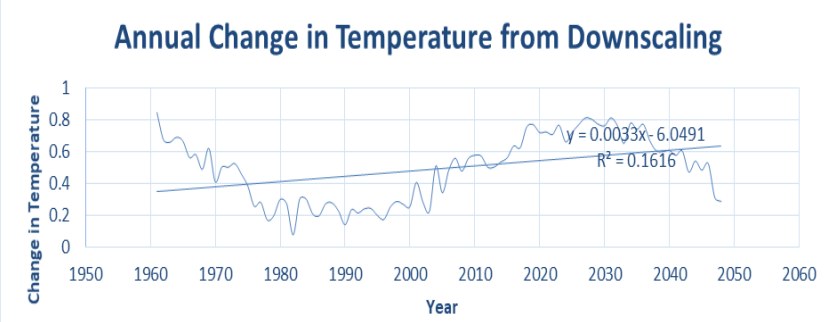

Fig. 7. Projected change in Annual Temperatures from Downscaled data

Using the statistical downscaling tool, the annual change in temperature was derived for the area of concern. An increasing trendline can be seen in Figure 7 given by the equation of $\mathrm{y}=0.0033 \mathrm{x}-6.0491$, and a coefficient of determination of 0.1616 . There is a convincing relationship between the variables as seen in the graph. It can be interpreted based on the trend that an increase of $0.0033^{\circ} \mathrm{C}$ is expected each year.

\subsection{Flood Frequency Curve}

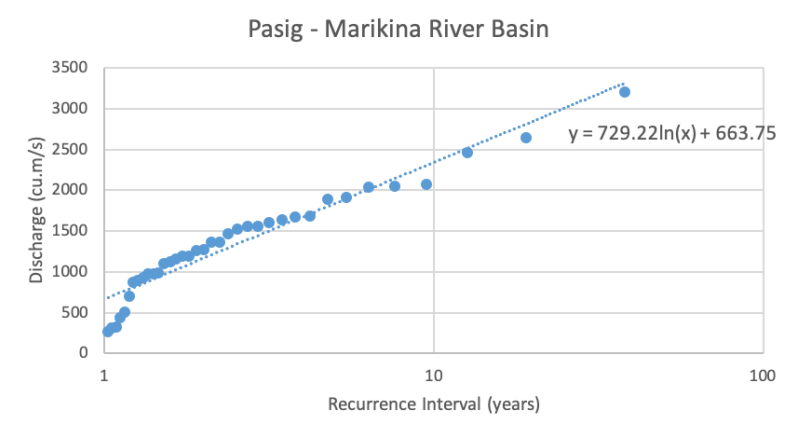

Fig. 8. Flood Frequency Curve

The researchers estimated probable frequency of floods based on annual maximum discharges at Sto. Niño (See Graph 10). The linear trend is observed to be at $\mathrm{y}=$ $729.22 \ln (x)+663.75$, where $y$ is the maximum discharge expressed in cu.m/s and $\mathrm{x}$ is the recurrence interval in years as shown in Figure 8. For the year 2048, the estimated maximum discharge follows the trend and is said to be at $3945 \mathrm{cu} . \mathrm{m} / \mathrm{s}$.

\subsection{Rainfall Time Series}

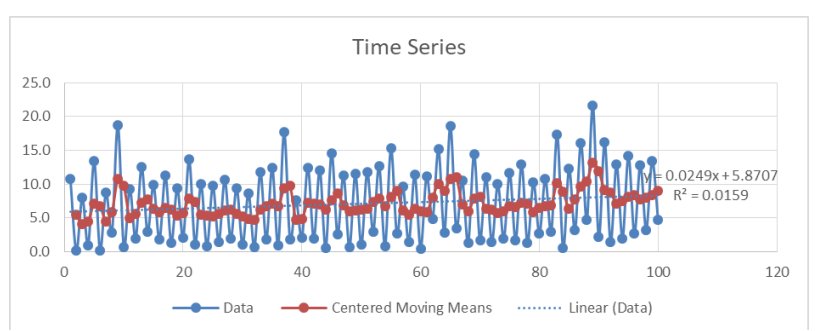

Fig. 9. Rainfall Time Series

Figure 9 the time series for rainfall in the Pasig-Marikina River basin using historical records on precipitation. The researchers arrived at this graph with $\mathrm{y}=0.0249 \mathrm{x}+5.8707$ trend line. Taking the mean of the individual seasonal effects gives the average seasonal effects of the area. The average seasonal effects are considered to smooth out the seasonal variation. The area of study has two distinct seasons according to the Modified Coronas Classification: wet from November to April and dry for the rest of the year. In year 2048 an amount of $15.2 \mathrm{~mm}$ average rainfall during the dry season while $4.6 \mathrm{~mm}$ average rainfall based on future rainfall projection.

\subsection{Land Cover Data}
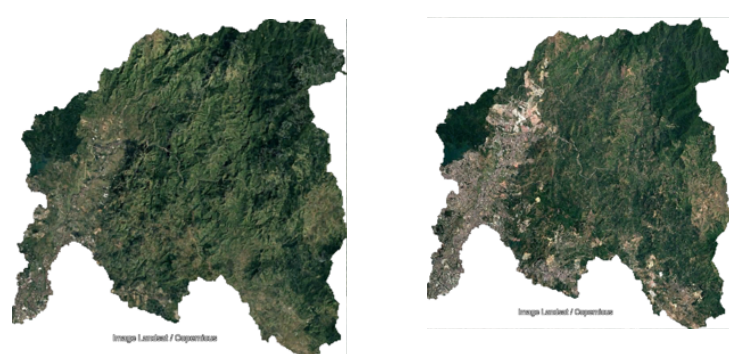

Fig. 10. Land Cover Maps (left 1984 and right 2016)

The maps of the Marikina River Basin in 1984 and 2016 (Figure 10) illustrate a significant change in the land cover of the study area. Based on the visual interpretation of the maps captured from Google Earth Pro, a large reduction of brushland area is shown in the east portion of the basin. The results revealed the greatly increase of built-up (establishments) also in the east portion and south portion of the basin.

\subsection{Rating Curve}

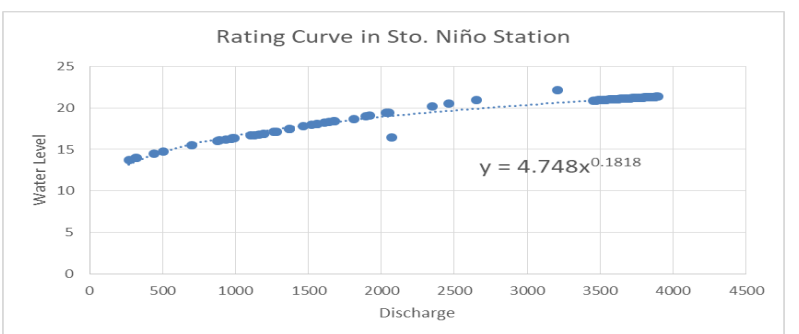

Fig. 11. Water level vs Discharge of Marikina River in Sto Nino station 
Figure 11 shows the rating curve for Marikina River taking the data from Sto. Niño station. The relationship is expressed by the power function of $y=4.748 x^{\wedge} 0.1818$ with $y$ representing the water level and $x$ for the discharge. For the year 2048, when the discharge reaches $3950 \mathrm{cu} . \mathrm{m} / \mathrm{s}$, the average water level is expected to have an annual average of $21.34 \mathrm{~m}$ which is considered a $3 \mathrm{rd}$ alarm according to Marikina River's water level monitoring.

\subsection{Flood Hazard Map from ArcGIS}

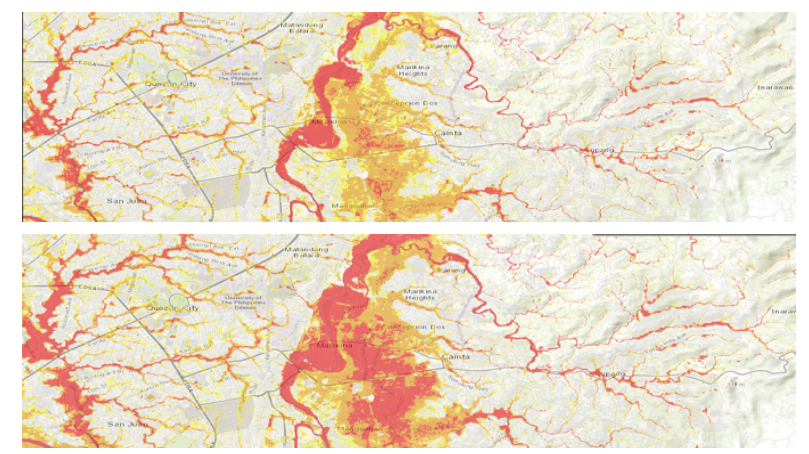

Fig. 12. Flood Hazard map of Marikina (upper 2018 and lower 2048)

Figures shows the flood hazard map of Marikina City based on different rainfall scenarios considering the impact of climate change. From lower Figure 12, high flood hazard is remarked to be dominant in the flood hazard map for the next twenty-five years. Most areas of Marikina City will expect high risk of flooding.

\section{Conclusion}

This study focused on the determination of the impact of climate change on the frequency and severity of floods in the Pasig-Marikina River basin. The atmospheric data (rainfall and temperature) from PAG-ASA was coupled with the climate model, HadCM3 to account for the natural variability of the climatic system in study. The observed atmospheric data from PAG-ASA covers the year 1961-2017. Through a series of multiple linear regressions and statistical analysis from the Statistical Downscaling Model (SDSM), the amount of precipitation for the year 1961-2001 and change in temperature were generated for the time span of 20182048. Projections on the amount of precipitation for the year 2018-2048 were obtained through the generation of the rainfall time series while taking into consideration; the average seasonal effects in the area. Meanwhile, a flood frequency curve is generated based on the available data on water level and water discharge in a stretch of the river basin which is in Sto. Niño.

It was projected that the annual rainfall depth will increase by $0.0399 \mathrm{~mm}$ per year. Considering the average seasonal effects of \pm 5.3 , rainfall depth will increase by $0.0249 \mathrm{~mm}$ per year. Likewise, the average temperature in the area will increase for the next 30 years with an incremental increase of $0.0033^{\circ} \mathrm{C}$ each year starting from the baseline year of 1961. The researchers were able to estimate for the future discharge in the river basin. The projection for the year 2048 is about $3,950 \mathrm{cu} . \mathrm{m} / \mathrm{s}$.

In addition, changes in land use impact the pattern of floods in the area. About half of the river basin is protected areas under the authority of DENR. The remaining areas are mostly owned by private sectors. Rapid population growth and urban sprawl contributed to increase in flooding due to impermeable ground surface

\section{References}

1. R. A. Badilla. Flood Modelling on Pasig-Marikina River Basin (2008)

2. R. Wilby. SDSM - a decision support tool for the assessment of regional climate change impacts. Environmental Modelling Software, 145-157 (2002)

3. A. Mareuil, R. L.. Impacts of climate change on the frequency and severity of floods in the Chateauguay River basin, Canada (2006)

4. K. Hamed, \& A. R. Rao. Flood Frequency Analysis (1999)

5. P. B. Hunukumbura, \& Y. Tachikawa. River Discharge Projection under Climate Change in the Chao Phraya River Basin, Thailand, Using the MRIGCM3.1S Dataset. Journal of the Meteorological Society of Japan. Ser. II, 90, 137-150. (2012)

6. J. R. Santillan, E. C. Near-real time flood extent monitoring in marikina river philippines: model parameterisation using remotely-sensed data and field measurements. (2012)

7. National Disaster Education Coalition. Talking about disaster: Guide for standard messages: Produced by the National Disaster Education Coalition. 63-64 . (1999)

8. J. D. Neelin. Climate Change and Climate Modelling. New York: Cambridge University Press. (2011)

9. T. Reichler a. How Well Do Coupled Models Simulate Today's Climate? 303-311. (2008)

10. P. S. Stott, External Control of 20th Century Temperature by Natural and Anthropogenic Forcings. 2133-2137 (2000)

11. J. T. Villarin, . 2016 Philippine Climate Change Assessment (PhilCCA): The Physical Science Basis. The Oscar M. Lopez Center for Climate Change Adaptation and Disaster Risk Management Foundation Inc. and Climate Change Commission. (2016) 